\title{
Cellular differentiation, bioactive and mechanical properties of experimental light-curing pulp protection materials
}

\author{
Salvatore Sauro ${ }^{a, b, *}$, Ashvin Babbar $^{b}$, Borzo Gharibi $^{b}$, \\ Victor Pinheiro Feitosa ${ }^{c, d}$, Ricardo Marins Carvalho ${ }^{e}$, \\ Lidiany Karla Azevedo Rodrigues ${ }^{c}$, Avijit Banerjee ${ }^{b, f}$, Timothy Watson ${ }^{b, f}$ \\ a Dental Biomaterials and Minimally Invasive Dentistry, Departmento de Odontologia, Facultad de Ciencias de la \\ Salud, CEU-Cardenal Herrera University, Alfara del Patriarca, 46115 Valencia, Spain \\ b Tissue Engineering and Biophotonics Research Division, King's College London Dental Institute, King's Health \\ Partners, London, UK \\ c School of Dentistry, Faculty of Pharmacy, Dentistry and Nursing, Federal University of Ceará, Fortaleza, Brazil \\ d Paulo Picanço School of Dentistry, Fortaleza, Brazil \\ e Department of Oral Biological and Medical Sciences, Division of Biomaterials, Faculty of Dentistry, The University \\ of British Columbia, Vancouver, BC V6T 1Z3, Canada \\ ${ }^{\mathrm{f}}$ Department of Conservative \& MI Dentistry, King's College London Dental Institute, King's Health Partners, \\ London, UK
}

\section{A R T I C L E I N F O}

Article history:

Received 1 November 2017

Received in revised form

31 December 2017

Accepted 27 February 2018

Keywords:

Bioactivity

Biocompatibility

Fracture toughness

Flexural strength

Cell differentiation

Pulp protection

\begin{abstract}
A B S T R A C T
Objective. Materials for pulp protection should have therapeutic properties in order to stimulate remineralization and pulp reparative processes. The aim of this study was to evaluate the mechanical properties, biocompatibility, cell differentiation and bioactivity of experimental light-curable resin-based materials containing bioactive micro-fillers.

Methods. Four calcium-phosphosilicate micro-fillers were prepared and incorporated into a resin blend: 1) Bioglass $45 \mathrm{S5}$ (BAG); 2) zinc-doped bioglass (BAG-Zn); 3) $\beta$ TCP-modified calcium silicate $(\beta-C S) ; 4)$ zinc-doped $\beta$-CS $(\beta-C S-Z n)$. These experimental resins were tested for flexural strength (FS) and fracture toughness (FT) after $24 \mathrm{~h}$ and 30 -day storage in simulated body fluid (SBF). Cytotoxicity was evaluated using MTT assay, while bioactivity was evaluated using mineralization and gene expression assays (Runx-2 \& ALP).

Results. The lowest FS and FT at $24 \mathrm{~h}$ was attained with $\beta$-CS resin, while all the other tested materials exhibited a decrease in FS after prolonged storage in SBF. $\beta$-CS-Zn maintained a stable FT after 30-day SBF aging. Incorporation of bioactive micro-fillers had no negative effect on the biocompatibility of the experimental materials tested in this study. The inclusion of zinc-doped fillers significantly increased the cellular remineralization potential and expression of the osteogenic genes Runx2 and ALP ( $p<0.05)$.
\end{abstract}

\footnotetext{
* Corresponding author at: Dental Biomaterials, Preventive and Minimally Invasive Dentistry, Departamento de Odontología, Facultad de Ciencias de la Salud, Universidad CEU-Cardenal Herrera, C/Del Pozo s/n, Alfara del Patriarca, 46115 Valencia, Spain.

E-mail address: salvatore.sauro@uch.ceu.es (S. Sauro).

https://doi.org/10.1016/j.dental.2018.02.008

0109-5641/@ 2018 The Academy of Dental Materials. Published by Elsevier Ltd. All rights reserved.
} 
Significance. The innovative materials tested in this study, in particular those containing $\beta$-CS-Zn and BAG-Zn may promote cell differentiation and mineralization. Thus, these materials might represent suitable therapeutic pulp protection materials for minimally invasive and atraumatic restorative treatments.

(c) 2018 The Academy of Dental Materials. Published by Elsevier Ltd. All rights reserved.

\section{Introduction}

The operative treatment of deep carious lesions can be challenging especially when approaching the pulp as the increased risk of pulp exposure during excavation can reduce the probability of pulp survival [1]. An ideal pulp protection material for such scenarios should be highly biocompatible and bioactive [2,3]. This is especially relevant with the contemporary minimally invasive restorative philosophy where contaminated (caries-infected) dentin is removed from deep cavity selectively, retaining most of the demineralized but repairable (caries-affected) dentin for potential remineralization as well as avoiding pulp exposure [4,5]. Indeed, clinicians are increasingly relying on restorative ion-releasing materials such calcium silicate cements to seal the restored interfaces in order to help remineralize the caries-affected tissues [6].

In certain clinical cases, indirect and/or direct pulp protection may help maintain pulp sensibility by facilitating healing/repair. Materials used for this purpose should interact with the pulp cells to stimulate the formation of reparative dentin [7-9]. Calcium silicate and MTA-like cements have been used as they can encourage remineralization and dentin bridge formation with no/minimal inflammatory pulp response [9-11]. However, their use as a bio-interactive restorative material is limited due to shortcomings in their mechanical properties, setting time and dissolution rate $[12,13]$. It is hypothesized that the formulation of resinmodified bioactive cements might present a solution to combine the best of both resin-based technology with the bioactivity of such cements. Indeed, resin-modified calcium silicate cement-based materials such as Theracal LC (BISCO, Chicago, IL, USA), a light-curable material advocated for direct and indirect pulp protection, showed greater compressive and flexural strengths compared to conventional calcium silicate cements, being more able to resist fracture during immediate placement of a definitive overlying restoration [14]. Nevertheless, such a resin-modified calcium silicate cement-based material demonstrated a reduction in cellular metabolism and protein expression. It was also exhibited greater cytotoxicity compared to conventional calcium silicate cements [15].

Sodium calcium phosphosilicates (e.g. Bioglass 45S5, BAG) have been used successfully in orthopedics as regenerative materials for bone $[8,16]$. In particular, BAG has been shown to induce calcium-phosphate precipitation, subsequently converting to hydroxyapatite-like crystallites $[8,17]$. Within dentistry, BAG is used in toothpastes and also as powders for dental air-abrasion/polishing to remineralize the dental hard tissues as well as treating dentin hypersensitivity $[18,19]$. Bioactive glasses are so called due to their in loco remineralization of tissues, but they cannot be used in as a definitive dental restorative material unless incorporated into a resin-based matrix $[20,21]$.

The aim of this study was to evaluate the mechanical properties, biocompatibility, cell differentiation and bioactivity of experimental light-curable resin-based materials containing bioactive micro-fillers for their potential use as indirect pulp protection materials, after storage in simulated body fluid (SBF). The mechanical properties were assessed through the evaluation of their flexural strength (FS) and fracture toughness (FT). The cytotoxicity of the tested materials was tested using MTT assay, while cell differentiation and mineralization were assessed using gene expression assays (Runx-2 and ALP). The bioactivity of the tested materials was evaluated using Raman spectroscopy and scanning electron microscopy (SEM). The null hypotheses tested in this study were that the addition of bioactive micro-fillers: 1) would have no effect on mechanical properties of the experimental resin-based materials tested; 2) would neither increase cytotoxicity nor induce differentiation in primary human mesenchymal stem cells (MSCs).

\section{Materials \& methods}

\subsection{Formulation of the resin-based bioactive materials}

A control filler-free resin (RES) was made using three hydrophobic monomers (55 wt\% urethane dimethacrylate and, $4.5 \mathrm{wt} \%$ bisphenol A diglycidildimethacrylate, $10.5 \mathrm{wt} \%$ triethylene glycol dimethacrylate, Sigma-Aldrich, Gillingham, UK), 20 wt\% 2-hydroxyethyl methacrylate (Sigma-Aldrich), $8.5 \mathrm{wt} \%$ absolute ethanol (Sigma-Aldrich) and a photo-initiating complex comprising $0.5 \mathrm{wt} \%$ camphorquinone/1.0 wt\% ethyl 4-dimethylaminobenzoate (Sigma-Aldrich). The experimental ion-releasing resins were formulated using 40 vol\% micro-filler and 60 vol\% resin blend [21]. Four experimental light-curable resin-based materials containing tailored bioactive micro-fillers were formulated as described by Sauro et al. [21]. In brief, Bioglass $45 \mathrm{~S} 5$ (BAG) micro-filler $(<20 \mu \mathrm{m}$ size) was sintered and incorporated within the composition of the control light-curable resin blend. The second micro-filler, BAG-Zn $(<20 \mu \mathrm{m})$, was created by modifying the composition of the BAG with $20 \mathrm{wt} \%$ zinc oxide (ZnO: Sigma-Aldrich) and a $10 \mathrm{wt} \%$ polycarboxylic acid solution (PAA: $\mathrm{M}_{\mathrm{W}}$ 1800; Sigma-Aldrich) and finally incorporated into the light-curable resin blend. The third micro-filler ( $\beta-C S)$ was formulated by modifying the composition of a type I ordinary Portland cement (OPC: Italcementi Group, Cesena, Italy) by adding $10 \mathrm{wt} \% \quad \beta$-tri-calcium phosphate [ $\beta$ TCP: $\mathrm{Ca}_{3}\left(\mathrm{PO}_{4}\right)_{2}$ (Sigma-Aldrich)]. The cement was mixed in deionized water (ratio 2:1 powder/liquid) and allowed to set 
in an incubator at $37^{\circ} \mathrm{C}$ for $24 \mathrm{~h}$. The set cement was subsequently ground and sieved as described previously [30] until $<20 \mu \mathrm{m}$ particle size was achieved. The fourth micro-filler $(\beta-C S-Z n)$ used in this study was created by mixing $70 \mathrm{wt} \%$ OPC, 20 wt\% $\mathrm{ZnO}$ and $10 \mathrm{wt} \% \beta$ TCP in $\mathrm{H}_{2} \mathrm{O}$ (ratio 2:1). After setting for $24 \mathrm{~h}$ at $37^{\circ} \mathrm{C}$, the micro-filler was treated (ratio $1: 1$ ) in a polymer flask with a 10 vol\% polyacrylic acid (PAA) solution for $15 \mathrm{~min}(45 \mathrm{rpm})$ and incubated in a furnace at $40^{\circ} \mathrm{C}$ for $12 \mathrm{~h}$. The resulting product was finally re-ground and sieved $(<20 \mu \mathrm{m})$. These latter micro-fillers were incorporated also into the light-curable resin blend as previously described.

\subsection{Flexural strength test (FS)}

Light curing resin-based specimens prepared in accordance with ISO $4049(25 \mathrm{~mm} \times 2 \mathrm{~mm} \times 2 \mathrm{~mm})$ may receive a non-uniform distribution of energy during the photopolymerization procedure, which may in turn, affect their flexural strength. Therefore, smaller specimen $(10 \mathrm{~mm} \times 2 \mathrm{~mm} \times 2 \mathrm{~mm})$ were used in this study to reduce the variable effect of polymerization as described in a previous study [22]. The experimental resin-based materials were inserted into rectangular silicone molds. A glass slide along with a plastic strip were placed on top to achieve parallel surfaces with no air bubbles. The specimens were light-cured $\left(>1000 \mathrm{~mW} / \mathrm{cm}^{2}\right)$ from both sides for $1 \mathrm{~min}$ using a LED light curing unit (Litex 695, Dentamerica Inc., Industry, CA, USA). Twelve specimens $(n=12)$ were prepared for each experimental resin cement as well as the control resin blend. The specimens were stored for $24 \mathrm{~h}$ at room temperature, half $(n=6)$ were tested, and the other half $(n=6)$ were further incubated for 30 day at $37^{\circ} \mathrm{C}$ in simulated body fluid solution (SBF) [21]. All samples were tested using a universal testing machine (Instron 5569) with a $500 \mathrm{~N}$ load cell and crosshead speed of $0.5 \mathrm{~mm} / \mathrm{min}$ using a 3-point bending system. The maximum fracture load (Newton) for each specimen was recorded and the flexural strength in MPa was calculated according to the equation:

Flexure strength $=3 \mathrm{FL} / 2 \mathrm{bd}^{2}$, where $\mathrm{W}=$ width and

$\mathrm{H}=$ height of the specimens.

Two-way ANOVA statistical analysis with a significance level of 0.05 and a Tukey's post-hoc test were performed with the resin blends as independent variables and the FS as the dependent variable (Sigma Stat ${ }^{\circledR}$, Version 3.5, Systat Software Inc., Point Richmond, USA).

\subsection{Fracture toughness test (FT)}

The FT $\left(\mathrm{K}_{\mathrm{IC}}\right)$ was measured according to the ASTM standards (E 399-83), using single-edge notched-beam specimens [23]. Twelve specimens $(16 \mathrm{~mm} \times 2 \mathrm{~mm} \times 2 \mathrm{~mm})$ for each experimental group were created using bar-shaped silicone molds and by compressing the material using a glass slide and finally light-cured as described previously. After removal from the mold, the specimens were ground with silicon carbide sand paper (grit size \# 1200/4000) to remove any excess material on the specimens' edges. All specimens were then stored in distilled water at $37^{\circ} \mathrm{C}$ prior to testing for $24 \mathrm{~h}$. A notch $(0.3 \mathrm{~mm}$ wide, $1 \mathrm{~mm}$ deep) was created for each specimen with a diamond saw under water irrigation. The width of the notch was determined by the thickness of the blade, whereas the standardization of the notch's depth was assured by a sliding depth-gauge mechanism installed on the saw, to $1 \mathrm{~mm}$ intrusion. The depth of the notch was measured with a digital microscope (CY-800B, Tokyo, Japan). The resin specimens were subjected to the same two environments, $24 \mathrm{~h}(\mathrm{n}=6)$ at room temperature and incubated for 30 days $(n=6)$ at $37^{\circ} \mathrm{C}$ in SBF. Specimens were tested using an Instron 5569 machine in a 3-point bending test, where the supporting length $[(S)=4 \mathrm{~W}]$ was $16 \mathrm{~mm}$. The samples were loaded until failure, using a crosshead speed of $0.5 \mathrm{~mm} / \mathrm{min}$. During testing, the specimens were immersed in distilled water at room temperature. The force during bending of the specimen was measured as a function of its deflection. Load versus deflection plots were recorded and the maximum load $(P)$ before failure was measured. The height (B) and width (W) of the specimens were measured with a micrometer and the notch depth (a) with a measuring microscope. The $\mathrm{K}_{\mathrm{IC}}$ was calculated according to the equation shown below, from measurements with the single-edge notched-beam specimens $\left(\mathrm{MPa} \mathrm{m}^{0.5}\right)$.

$$
\mathrm{K}_{\mathrm{IC}}=\frac{3 \sqrt{a / \mathrm{W}}\left[1.99-a / \mathrm{W}(1-a / \mathrm{W})\left(2.15-\frac{3.93 a}{\mathrm{~W}}+2.7(a / \mathrm{W})^{2}\right)\right] P S}{2(1+2 a / \mathrm{W}) \sqrt{(1-a / \mathrm{W})^{3} \mathrm{BW}^{3}}}
$$

Two-way ANOVA statistical analysis with a significance level of 0.05 and a Tukey's post-hoc test were performed with the resin blends as independent variables and the FS as the dependent variable (Sigma Stat ${ }^{\circledR}$, USA).

\subsection{Bioactivity evaluation through Raman spectroscopy and SEM}

The specimens used in the FS test were also analyzed at $24 \mathrm{~h}$ and after 30 day of SBF storage using Raman spectroscopy and SEM. In brief, three specimens for each group were scanned in wet conditions using a computer-controlled confocal laser Raman spectro-microscope (Horiba Scientific Xplora, Villeneuved'Ascq, France) equipped with optical X20 objective and CCD detector attached to a modular research spectrograph. A near-infrared diode laser spot-size of $\leq 1 \mathrm{\gamma m}$ operating at $785 \mathrm{~nm}$ was used to induce the Raman scattering effect. Raman signals were acquired using a 600 -lines $/ \mathrm{mm}$ grating centered between $500-1000 \mathrm{~cm}^{-1}$. The calibration of wavelength and intensity was performed according to manufacturer's specification using a silicon standard and the calibration system integrated with the software [17,24]. One surface of each specimen was scanned in three different areas (ROI: $1 \mathrm{~mm} \times 1 \mathrm{~mm}$ ), and then submitted to $\mathrm{K}$-means cluster (KMC) analysis as described by Sauro et al. [2] using multivariate analysis, which included statistical patterning to derive independent clusters. The biochemical content of each cluster was analyzed using the average cluster spectra. Principal component analysis (PCA) data were set into a bilinear model of linear independent variables, the so-called principal components (PCS). Two to four clusters were identified but only two representative clusters such as resin and mineralization (peak 
at $961 \mathrm{~cm}^{-1}$ as reference) were obtained independently and considered in this study. All the specimens used for Raman spectroscopy analysis were dehydrated in increasing concentrations of ethanol (50\% - $20 \mathrm{~min}$; $75 \%$ - $20 \mathrm{~min}$; $90 \%$ - $30 \mathrm{~min}$; 95\% twice $-30 \mathrm{~min}$; $100 \%$ twice $-30 \mathrm{~min}$ ) and desiccated for $24 \mathrm{~h}$ at $3^{\circ} \mathrm{C}$. They were mounted on aluminum stubs using carbon tape, gold sputter coated and finally analyzed through FEG-SEM (S4000 Hitachi, Tokyo, Japan) at $3 \mathrm{kV}$.

\subsection{Evaluation of the alkalinizing activity $(p H)$}

Three resin-disk specimens were prepared for each tested material using silicon molds $(\varnothing=6 \mathrm{~mm} ; \mathrm{h}=1 \mathrm{~mm})$ and lightcured for $40 \mathrm{~s}$ using a LED curing system (Litex 695, USA) as previously described (see Section 2.4). The specimens were immersed in $25 \mathrm{ml}$ of deionized $\mathrm{H}_{2} \mathrm{O}$ ( $\mathrm{pH}$ 6.8) in polypropylenesealed containers stored at $37^{\circ} \mathrm{C}$. The $\mathrm{pH} /$ alkalinizing activity was evaluated using a professional $\mathrm{pH}$ electrode (MettlerToledo, Leicester, UK) at $37^{\circ} \mathrm{C}$ after 1 day, 15 day, 30 day. The $\mathrm{H}_{2} \mathrm{O}$ was replaced over each measurement period.

\subsection{Cell culture}

Human mesenchymal stem cells basal medium (MSCs: ref. PT3238, Lonza), (Lonza Group Ltd., Basel, Switzerland) [25] were cultured in $\alpha$-Minimal Essential Medium (MEM) containing penicillin $(50 \mathrm{U} / \mathrm{ml})$, streptomycin $(50 \mu \mathrm{g} / \mathrm{ml})$ (all from Sigma-Aldrich, Poole, Dorset, UK), Glutamax (2 mM) (Invitrogen, Paisley, UK) and 10\% fetal bovine serum (FBS) (Sigma-Aldrich); cells were maintained at $37^{\circ} \mathrm{C}$ in a humidified $5 \% \mathrm{CO}_{2}: 95 \%$ air atmosphere. Three resin-disk specimens were prepared for each tested material using silicon molds $(\varnothing=6 \mathrm{~mm} ; \mathrm{h}=1 \mathrm{~mm}$ ) and light-cured for $40 \mathrm{~s}$ using a LED curing system (Litex 695, USA). Subsequently, the specimens were polished using SiC papers up to \#1000-grit under continuous distilled water (DW) irrigation. The specimens were then decontaminated by soaking in absolute ethanol for $10 \mathrm{~min}$. Cell monolayers were seeded into 24 -well plates with $5 \times 10^{4}$ cells $/ \mathrm{ml}$ and cultured in the presence of the experimental materials for 14 days immersed in an osteogenic media supplemented with $0.1 \mu \mathrm{M}$ dexamethasone, $0.05 \mathrm{mM}$ Ascorbic Acid (AA) and $10 \mathrm{mM}$ glycerophosphate (Sigma-Aldrich).

\subsection{Biological testing (MTT) and osteogenic differentiation (Runx-2 and ALP)}

Assessment of the biocompatibility of the experimental bioactive resin-based materials was performed in accordance with the ISO 10993-5 using a direct cytotoxicity test, MTT assay. In brief, after 14 days the media was replaced with a MTT solution (Methylthiazolyldiphenyl-tetrazolium bromide; Sigma-Aldrich) and incubated for $4 \mathrm{~h}$ at $37^{\circ} \mathrm{C}$. Subsequently, the MTT solution was replaced with DMSO (Dimethyl sulfoxide, $99.9 \%$, Sigma-Aldrich), and kept under continuous agitation (5 min) using an automatic chemical shaker (Titertek, Flow Laboratories). Finally, the absorbance of the MTT was measured on a microplate reader (Opsys MR, Dynex) at $570 \mathrm{~nm}$ wavelength with reference wavelength at $630 \mathrm{~nm}$. One-way ANOVA and Tukey's test $(p<0.05)$ were performed to analyze the data (Sigma Stat ${ }^{\circledR}$, USA). Live/Dead fluorescent stain- ing was performed to assess visually the effect of the resin blends on the MSCs. Here, solutions of $2 \mathrm{uM}$ calcein AM (Sigma-Aldrich) and $4 \mu \mathrm{M}$ ethidium homodimer in Dulbeccos's Phosphate Buffered Saline (PBS, Sigma-Aldrich) were used, the system then incubated for $10 \mathrm{~min}$ and assessed visually qualitatively using an Olympus X51 microscope coupled with an Olympus V-RFL-T camera, 10× magnification.

To assess osteogenic differentiation, mRNA expression of the markers of differentiation (i.e. Runx-2 and ALP) was determined by quantitative real-time polymerase chain reaction (RT-qPCR), while accumulation of calcium deposits was visualized by staining using Alizarin Red. Briefly, cells were fixed (15 min with $4 \%$ formaldehyde in PBS), stained for $10 \mathrm{~min}$ with alizarin red $\mathrm{S}$ (1:100 dilution in $\mathrm{H}_{2} \mathrm{O}$ ) and washed in 50\% ethanol and air-dried.

Total RNA was extracted using TRI reagent (Ambion, Warrington, UK) and Phase Lock Gel Heavy tubes (Five-prime VWR, Leicestershire, UK) according to the manufacturer's instructions. After RNA purity and quantity was assessed by nanodrop (Fisher Scientific, London, UK) (A $\mathrm{A}_{260} / \mathrm{A}_{280} 1.8-2$ was considered suitable for further analysis), possible contaminating DNA was removed and cDNA prepared from $1 \mu \mathrm{g}$ RNA using QuantiTect Reverse Transcription Kit (Qiagen, West Sussex, UK) according to the manufacturer's instructions. RT-qPCR was performed on a Mx3000P real time PCR system using Brilliant III Ultra-Fast SYBR Green qPCR Master mix (Stratagene, Agilent Technologies, Cheshire, UK) and the following primer pairs $\left(5^{\prime}-3^{\prime}\right)$ Runx-2 (AATGGTTAATCTCCGCAGGTC and TTCAGATAGAACTTGTACCCTCTGTT); ALP (AACACCACCCAGGGGAAC and TGGCATGGTTCACTCTCGT). PCR conditions consisted of 1 cycle of $95^{\circ} \mathrm{C}$ for $3 \mathrm{~min}$ and 40 cycles of $95^{\circ} \mathrm{C}$ for $10 \mathrm{~s}$ and $60^{\circ} \mathrm{C}$ for $20 \mathrm{~s}$. RPL13a was used as an invariant housekeeping gene. One-way ANOVA and Tukey's test $(p<0.05)$ were used to analyze the data (Sigma Stat ${ }^{\circledR}$, USA).

Alizarin red staining (ARS) staining was performed to determine the mineralization ability of the tested materials on the cells in each well plate $(n=3)$. After 14 days of incubation, the cells were rinsed, fixed with $10 \%$ formaldehyde for $30 \mathrm{~min}$, and stained with $40 \mathrm{mM}$ alizarin red $\mathrm{S}$ ( $\mathrm{pH} 4.2$ ) for $30 \mathrm{~min}$. After staining, the morphology was observed using light microscopy (Olympus 1X71, Shinjuku, Tokyo, Japan).

\section{Results}

\subsection{Flexural strength (FS) and fracture toughness (FT)}

The mean and standard deviation of the results obtained with the flexural strength $(\mathrm{MPa})$ and fracture toughness $\left(\mathrm{MPa}^{0.5}\right)$ are depicted in Table 1 . At $24 \mathrm{~h}$ there was no significant difference in FS between the experimental resins and the control filler-free resin (RES), ( $p>0.05)$. However, all the tested experimental resins showed a significant drop in FS after AS storage for $30 \mathrm{~d}(\mathrm{p}<0.05)$; there was no significant $\mathrm{FS}$ reduction in the RES specimens $(p>0.05)$. Mean FS was affected by the material type $(F=99.61 ; p<0.001)$, and by storage time $(F=56.9$; $\mathrm{p}<0.001)$.

At $24 \mathrm{~h}$ there was no significant difference in FT between the experimental resins and the RES group ( $p>0.05)$. Conversely, only the RES, experimental resin-based materials BAG 
Table 1 - Flexural strength (FS) and fracture toughness (FT) of experimental resins after $24 \mathrm{~h}$ and 30 day ageing in AS at $37^{\circ} \mathrm{C}$.

\begin{tabular}{lllll} 
& \multicolumn{2}{c}{ Flexural strength (FS; MPa) } & & \multicolumn{2}{c}{ Fracture toughness (FT; MPa.m.5) } \\
\cline { 2 - 3 } & $24 \mathrm{~h}$ & 30 day & $24 \mathrm{~h}$ & 30 day \\
\hline RES & $98.0 \pm 12.9[\mathrm{~A} 1]$ & $99.2 \pm 11.2[\mathrm{~A} 1]$ & $2.7 \pm 0.5[\mathrm{~A} 1]$ & $2.0 \pm 0.2[\mathrm{~A} 2]$ \\
BAG & $88.4 \pm 15.6[\mathrm{~A} 1]$ & $48.0 \pm 5.6[\mathrm{~B} 2]$ & $2.4 \pm 0.5[\mathrm{~A} 1]$ & $1.2 \pm 0.2[\mathrm{~B} 2]$ \\
BAG-Zn & $91.3 \pm 13.4[\mathrm{~A} 1]$ & $53.1 \pm 9.4[\mathrm{~B} 2]$ & $2.5 \pm 0.4[\mathrm{~A} 1]$ & $1.9 \pm 0.2[\mathrm{~A} 1]$ \\
$\beta$-CS & $85.3 \pm 16.4[\mathrm{~A} 1]$ & $55.6 \pm 7.1[\mathrm{~B} 2]$ & $1.9 \pm 0.4[\mathrm{~A} 1]$ & $1.3 \pm 0.3[\mathrm{~B} 2]$ \\
$\beta$-CS-Zn & $79.6 \pm 8.6[\mathrm{~A} 1]$ & $50.9 \pm 8.4[\mathrm{~B} 2]$ & $2.3 \pm 8.5[\mathrm{~A} 1]$ & $2.1 \pm 0.1[\mathrm{~A} 1]$ \\
\hline
\end{tabular}

Similar uppercase letter indicates no significant differences in column at $24 \mathrm{~h}$ or 30 day $(\mathrm{p}>0.05)$.

Similar number indicates no significant differences in row between $24 \mathrm{~h}$ and 30 day $(\mathrm{p}>0.05)$.

and $\beta$-CS showed a significant drop in FT after prolonged AS storage $(p<0.05)$. The other two experimental resins containing the zinc-doped fillers ( $\beta$-CS-Zn; BAG-Zn) had no significant drop in FT after 30 days of AS storage $(p>0.05)$. The mean FT was affected by the material type $(F=79.61 ; p<0.001)$, and by storage time $(\mathrm{F}=26.5 ; \mathrm{p}<0.001)$.

\subsection{Bioactivity and alkalinizing activity $(p H)$}

The Raman cluster spectra of each tested material obtained at $24 \mathrm{~h}$ and after 30 day of SBF storage are illustrated in Fig. 1 (A-H). It was observed that all the experimental resins containing the bioactive fillers presented, after cluster analysis, a prominent peak at $961 \mathrm{~cm}^{-1}$ after 30 day of AS storage, which indicated the formation of apatite. Conversely, the representative cluster of remineralization was never observed in specimens after $24 \mathrm{~h}$. These results were confirmed during the SEM assessment of the specimens after 30 days of SBF storage. Presence of apatite was detected in all the resins containing bioactive fillers. However, differences in apatite crystal morphology were observed between the resins containing the zinc-doped bioactive fillers (BAG-Zn and $\beta-C S-Z n$ ) and those containing BAG or $\beta$-TCS. No defined crystal structure was observed in the RES group. The specimens containing BAG and $\beta$-CS presented consistent precipitation of needle-like apatite crystallites (Fig. 1I). The resins BAG-Zn and $\beta-\mathrm{CS}-\mathrm{Zn}$ showed precipitation of crystallites of apatite with a globularlike structure (Fig. 1L).

The mean and standard deviation of $\mathrm{pH}$ values attained during the alkalinizing activity evaluation are illustrated in Fig. 2G. The resins containing the bioactive micro-fillers BAG or $\beta$-CS induced an increase of the $\mathrm{pH}$ of the storage solution at $15 \mathrm{~d}$ and 30 day. However, the $\beta$-CS resin showed the most alkalinizing potential with a $\mathrm{pH}$ of $12.6( \pm 0.3)$ at 15 day and 12.7 $( \pm 0.2)$ after 30 day of storage in $\mathrm{H}_{2} \mathrm{O}$. The resin containing BAG filler had slight alkalizing potential ( $\mathrm{pH} \sim 10.0)$. Conversely, the resins containing the $\mathrm{ZnO} /$ polycarboxylated fillers (BAG-Zn and $\beta-\mathrm{CS}-\mathrm{Zn}$ ) presented a more attenuated alkalinizing activity both at 15 day ( $\mathrm{pH} \sim 8.6 / 8.8$ ) and at 30 day ( $\mathrm{pH} \sim 9 / 9.1)$. The resin control (RES) presented no change at 15 day ( $\mathrm{pH} 6.7 \pm 0.2$ ), but this material induced slight acidification of the media after $30 \mathrm{~d}$ of storage in $\mathrm{H}_{2} \mathrm{O}(\mathrm{pH} 5.7 \pm 0.3)$.

\subsection{MTT biocompatibility and Live \& Dead assay}

The mean and standard deviation of the results obtained with MTT are presented in Table 2, while the qualitative results Live \& Dead are depicted in Fig. 2. In brief, all experimental resins led to a significant viability decrease $(p<0.01)$ compared to the cell control. However, filler-free resin (RES; Fig. 2A) and $\beta$-CS resin (Fig. 2B) led to cell death $(p<0.05)$. Cells had a spindlelike morphology during Live\&Dead fluorescence microscopy, which is indicative of cell death. Similar cell density and aspect was encountered for groups, BAG (Fig. 2C) and the two zinc-doped fillers BAG-ZN and $\beta-C S-Z n$ resin (Fig. 2D).

\subsection{Gene expression \& mineralization}

The mean and standard deviation of the results obtained with the gene expression assay are presented in Table 2. It was observed that MSCs grown in presence of the experimental materials differentiated into osteoblasts. Changes in markers of osteogenesis were analyzed by RT-qPCR and accumulation of mineralized matrix was visualized by alizarin red staining. MSCs differentiated in the presence of BAG showed slight effect on expression of either osteogenic markers, Runx-2 and ALP. Similarly, $\beta$-CS and control RES had no significant effect ( $p>0.01)$ on expression of osteogenic master switch (Runx2) and ALP expression. Interestingly, incorporation of $\mathrm{Zn}$ to either BAG or $\beta$-CS had potent osteogenic effect with significant increase in expression of both markers ( $p>0.01)$. Runx-2 expression was increased by more than five fold $(p<0.05)$ in both BAG-Zn and $\beta-C S-Z n$ and ALP level by more than fourfold $(p<0.05)$ when compared to cells cultured in presence of pure resin alone. The effect seen on mRNA expression of osteogenic genes by BAG-Zn (Fig. 2E) and $\beta$-CS-Zn (Fig. 2F) was also confirmed by the alizarin staining of calcium deposits.

\section{Discussion}

Pulp protection materials used in the atraumatic restorative treatment (ART) technique should be able to evoke remineralization with no inflammatory pulp response [9-13]. Accordingly, this study aimed at generating advanced lightcurable resin-based materials containing different types of experimental bioactive micro-fillers: evaluating their flexural strength, fracture toughness, biocompatibility, cell differentiation and bioactivity after storage in simulated body fluid (SBF). However, it is important to anticipate that the exper- 

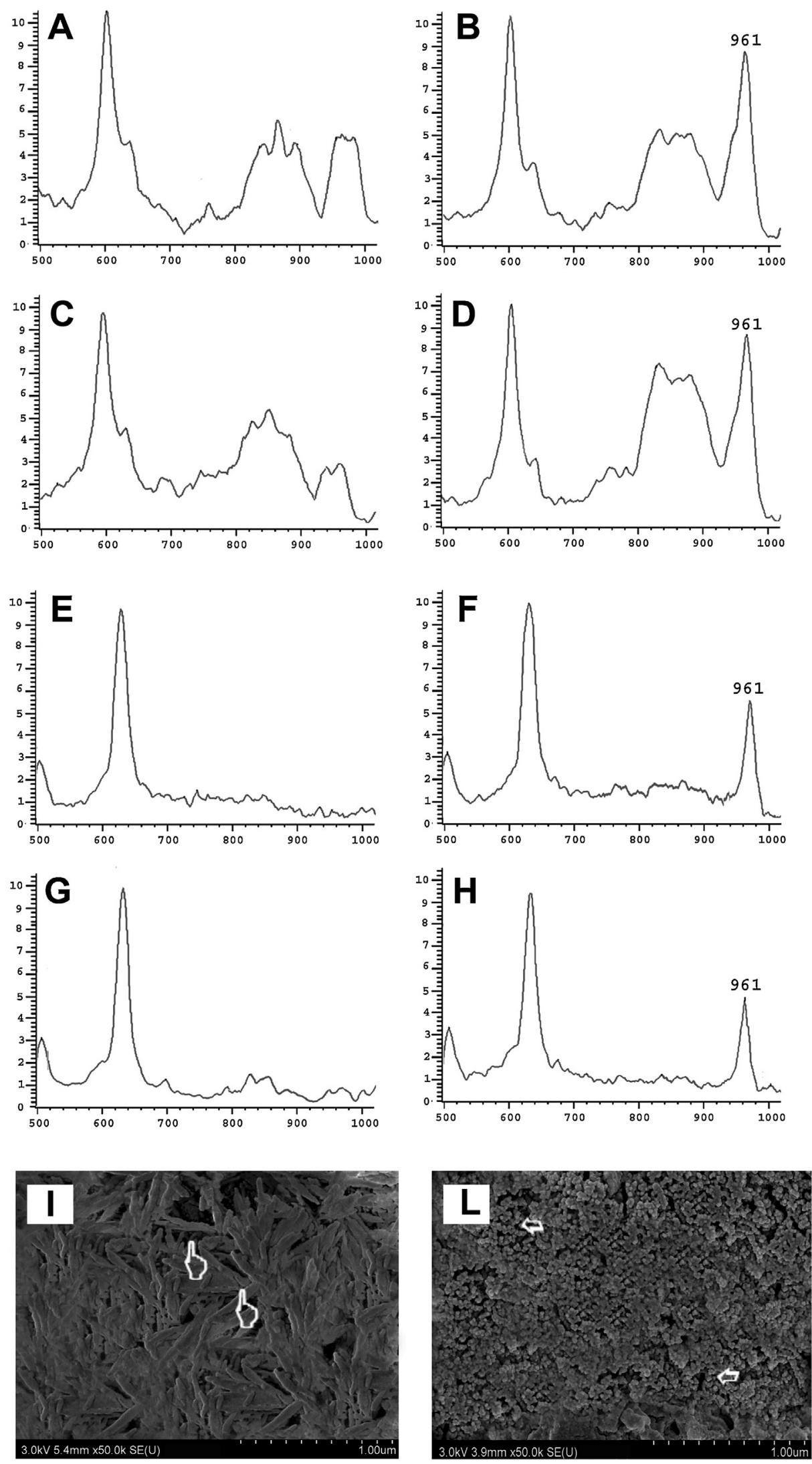

Fig. 1 - Raman spectroscopic cluster analysis of principal components identified before and after storage [resin and remineralization]. The resin BAG at $24 \mathrm{~h}$ showed a Raman resin cluster with no sign of $\mathrm{Ca} / \mathrm{P}$ minerals on the outer surface (A), while after 30 days of SBF storage, it was able to induce apatite precipitation (note the peak at $961 \mathrm{~cm}^{-1}$ ) (B). The same situation was observed with the resin BAG-Zn at $24 \mathrm{~h}$, which showed no sign of mineralization (C), but clear apatite 
Table 2 - Biocompatibility (MTT) and cell differentiation (gene expression Runx2 and ALP) of experimental resins after $24 \mathrm{~h}$ and 30 day ageing in AS at $37^{\circ} \mathrm{C}$.

\begin{tabular}{llll} 
& \multicolumn{1}{c}{ MTT } & \multicolumn{2}{c}{ mRNA gene expression } \\
\cline { 2 - 4 } & 14 days & Runx2 & ALP \\
\hline Cell-control & $0.5 \pm 0.01[\mathrm{~A}]$ & - & - \\
RES & $0.2 \pm 0.03[\mathrm{~B}]$ & $1.1 \pm 0.1[\mathrm{~A}]$ & $1.0 \pm 0.1[1]$ \\
BAG & $0.4 \pm 0.04[\mathrm{C}]$ & $1.74 \pm 0.5[\mathrm{~A}]$ & $1.3 \pm 0.3[1]$ \\
BAG-Zn & $0.4 \pm 0.04[\mathrm{C}]$ & $4.9 \pm 1.7[\mathrm{~B}]$ & $4.1 \pm 1.2[2]$ \\
$\beta$-CS & $0.1 \pm 0.05[\mathrm{D}]$ & $1.7 \pm 0.2[\mathrm{~A}]$ & $1.5 \pm 0.1[1]$ \\
$\beta$-CS-Zn & $0.4 \pm 0.05[\mathrm{C}]$ & $4.8 \pm 1.9[\mathrm{~B}]$ & $4.7 \pm 1.9[2]$ \\
\hline
\end{tabular}

Similar uppercase letter indicates no significant differences in column for MTT and Runx2 ( $>0.01)$.

Similar number indicates no significant differences in column for ALP $(p>0.001)$.

imental light-curable resin-based materials with bioactive micro-fillers assessed in this study have not been developed to be used as direct pulp-capping agents.

The flexural strength (FS) is representative of tensions developed in the dental cavities, as it encompasses tensile, compressive and shear stresses under bending loads. Although FS is a static single-movement mechanical test, it is usually the first choice to survey the preliminary physical properties of newly developed resin-based materials. It is well known that several internal and superficial defects/imperfections may be present in specimens and materials [3], even when they seem flat and smooth to the naked eye. Therefore, under masticatory forces, materials undergo not only flexural tensions, but also the need to resist fracture/crack propagation; this measure is known as fracture toughness (FT). In view of the results obtained with the present FS and FT tests, the first null hypothesis that the addition of bioactive micro-fillers would have no effect on mechanical properties of the experimental resin-based materials tested must be partially rejected. Indeed, this study showed that there was no significant difference in FS and FT at $24 \mathrm{~h}$ between the resin-based materials containing the experimental micro-fillers and the control filler-free resin. However, all the tested experimental materials showed a significant drop in FS after $30 \mathrm{~d}$ storage of SBF storage, while the specimens created with the filler-free resin (RES) showed no significant reduction.

A possible explanation for the FS results obtained with the specimens created using the resin-based materials containing the experimental micro-fillers is that such a reduction may be attributed to the hydrophilicity of the included fillers, which absorb quantities of water [20] to evoke the bioactive processes for mineral precipitation (Fig. 1A-H). However, although these types of bioactive resin-based materials may not be suitable as definitive restorative materials due to their higher water sorption and solubility compared to conventional dental resin composites, they can be used as a pulp protection or temporary therapeutic materials in the stepwise restorative technique [20].

The FT results showed a significant drop after 30 day storage of SBF storage only in the specimens created using the experimental BAG and $\beta$-CS and the filler-free resins. Conversely, the experimental resins $\beta-C S-Z n ; B A G-Z n$ showed no significant FT reduction (Table 1).

Such a drop in mechanical properties observed after prolonged aging in SBF (30 day) can be due to the high opacity (low reflection index) of some of the micro-fillers ( $40 \mathrm{vol} \%$ ) used in this study. These may have interfered with the photopolymerization due to an incomplete diffusion of the light (energy) throughout the bulk of material. Such a phenomenon was potentially responsible for the decrease of monomer conversion, which caused an accelerated degradation of the resin matrix over time, especially in the experimental BAG and $\beta$-CS resins [26]. Conversely, in the filler-free control resin, the reduction of fracture toughness may be attributed to the hydrolytic degradation upon SBF immersion, with hydrolysis and elution of the more linear polymer chains within the resin matrix [27].

The experimental micro-fillers, $\beta-C S-Z n$ and BAG-Zn, may have trigged a prolonged cationic polymerization within the polymer matrix. It is known that a cationic polymerization may be activated by polyionic silicates which form during the formulation of the BAG-Zn and $\beta$-CS-Zn micro-fillers treated with the polycarboxylic acidic solution [20,28,29]. Moreover, it has been stated that glass polyalkenoate cements containing zinc oxide may react with PAA and set via a two-step setting mechanism: 1) zinc-polyacrylate species cause primary hardening of the cement and later; 2) during water storage, formation of calcium-polyacrylate may induce a second post-hardening step. Furthermore, calcium ions released from the experimental micro-fillers may have reacted with the carboxylate group in the polyacrylic acid and stabilized the mechanical properties resin BAG-Zn and $\beta$ TCS-Zn during prolonged AS storage [30]. However, it is also likely that

precipitation (note the peak at $961 \mathrm{~cm}^{-1}$ ) after 30 days of SBF storage (D). The resin $\beta-C S$ (E) and the $\beta-C S-Z n$ (G) showed at $24 \mathrm{~h}$ showed only a Raman cluster with no sign of mineralization. These two resins $\beta-\mathrm{CS}(\mathrm{F})$ and the $\beta-\mathrm{CS}-\mathrm{Zn}(\mathrm{H})$ were able to induce apatite formation (note the peak at $961 \mathrm{~cm}^{-1}$ ) after 30 days of SBF storage. Figures I and L are representative SEM micrographs showing respectively a needle-like apatite formation (pointer) in resins containing filler that were not doped with zinc (BAG and $\beta-C S$ ) and globular-like nano-apatite formation (arrow) in resins containing the zinc-doped fillers (BAG-Zn and $\beta-C S-Z n$ ). 

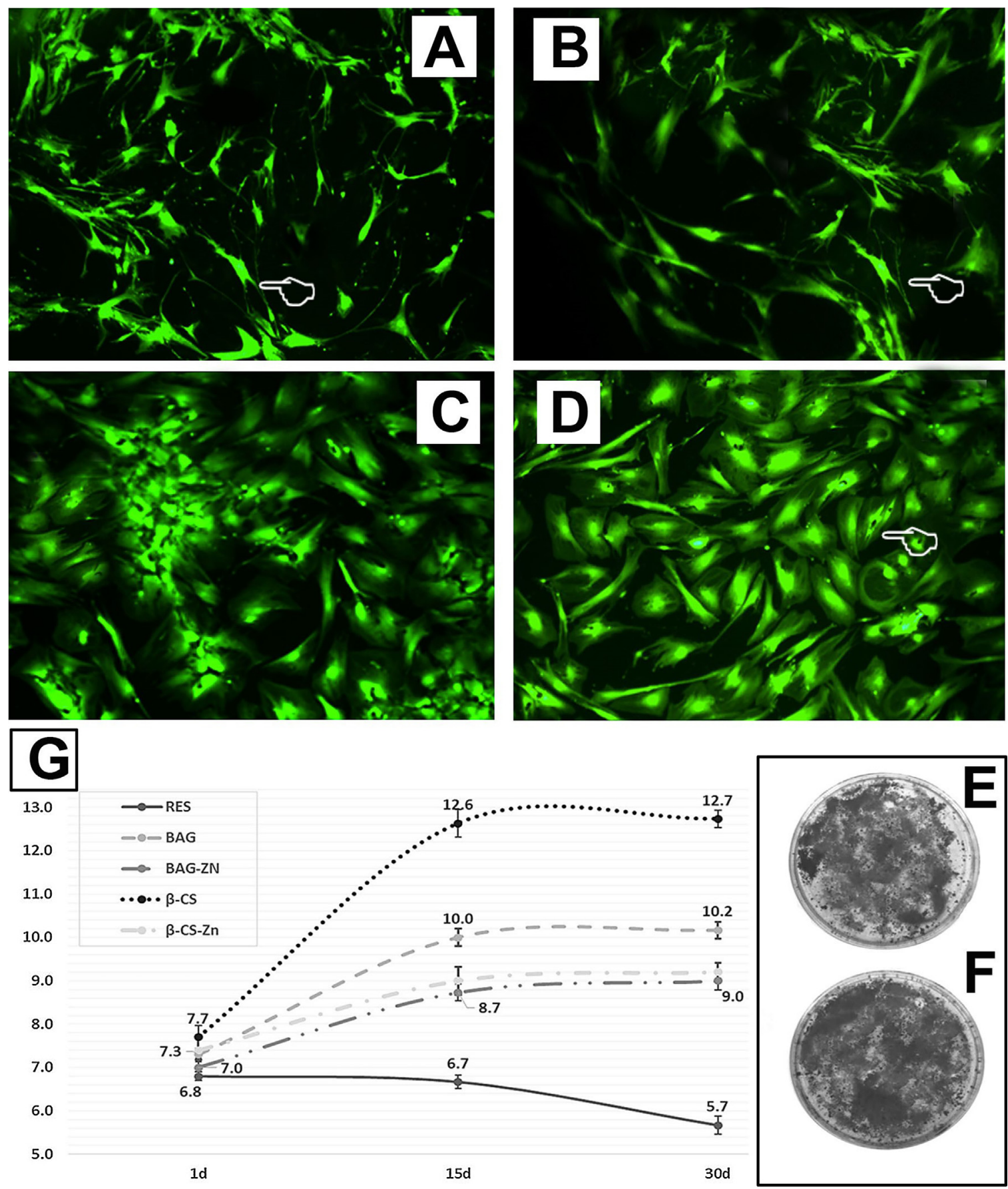

Fig. 2 - Images obtained during the Live\&Dead fluorescence microscopy. It is possible to see spindle-like cell morphology (pointer), which is indicative of cell death, in the group of the filler free resin (A) and $\beta$-CS resin (B). The group BAG, BAG-ZN and $\beta-C S-Z n$ presented similar cell density. Figure $C$ is a representative image obtained in presence of the BAG and figure $D$ is a representative image obtained with the resin containing the zinc-doped fillers (BAG-ZN and $\beta$-CS-Zn). In all cases, it is possible to see great cell density and a clear differentiation of the MSCs into fibroblasts (pointer). Fig. (E) and (F) are optical micrographs (alizarin red staining technique) that show the calcium deposits (dark areas) observed in the resins BAG-Zn and $\beta-C S-Z n$, respectively. In figure (G) it is reported the pH value of each material tested in this study. It is possible to see that the most alkalinizing resin was the $\beta-\mathrm{CS}$, which was able to maintain a strong alkaline $\mathrm{pH}$ over time [pH $>12]$. While the other experimental resins presented a milder $\mathrm{pH}$, in particular those containing the zinc-doped fillers.

bioactive ion leaching and the bioactive transformation of the fillers into needle-like apatite (Fig. 2I) at a strongly alkaline $\mathrm{pH}$ (Fig. 2G) may have created excessive micro-porosities within the experimental BAG and $\beta$-CS resins. This may have caused a significant reduction in FT over time [20]. The experimental BAG-Zn and $\beta$-CS-Zn resins showed globular-like apatite pre- 
cipitation (Fig. 2L) at mildly alkaline pH (Fig. 2G). In this case, it is hypothesized that the reduction in FT was less evident due to the fewer porosities within the material created by a more compact mineral precipitation. All the results described so far seem to be in accordance with those previously reported by Sauro et al. [20] and by Le et al. [31]. The latter team demonstrated that, in a strongly alkaline environment, $(\mathrm{pH} 10-11)$ apatite precipitates with a morphology characterized by clusters of acicular crystals (needle-like structures). At a mildly alkaline $\mathrm{pH}$ (8-9), apatite precipitates as globules of nanoparticles (globular-like structure) due to a fast nucleation rate so that more particles are formed and the nuclei of crystals grow slower due to the low temperature [32].

It is important to consider that the differences observed in these experimental resins in terms of $\mathrm{pH}$, kinetics of precipitation and morphology of the apatite may have influenced the biocompatibility and played a role in the cell growth/differentiation. Indeed, the present results showed that all the resin-based materials tested led to a significant cell viability decrease (MTT test) compared to the negative control where the cells were seeded in the absence of resinbased material. However, the filler-free resin (RES) and $\beta$-CS resin induced cytotoxicity and the cells showed a spindle-like morphology, indicative of cell death (Fig. 2A and B). The effects of the tested materials on the mineralization potential were investigated at the mRNA level, enzymatic level (ALP only) and extracellular matrix mineralization level (Alizarin red staining). The RES and $\beta$-CS showed no significant effect on the expression of the osteogenic markers, Runx-2 and ALP. All these outcomes encountered with the $\beta$-CS resin may have been a consequence of the ability of such material to make the medium alkaline over time (Fig. 2G) [33]. Moreover, it is speculated that there may have been an important elution of unreacted monomers in all resins [27]. This led to a significant cell viability reduction compared to the control (no resin material). Previously, the possibility of a low degree of conversion in the $\beta$-CS due to a lack of photo-polymerization was discussed. In this case, it may have caused the elution of unreacted monomers and initiator/co-initiator agents causing greater cytotoxicity with the $\beta$-CS resin $[34,35]$. Leaching of such components may accumulate over time to a toxic level, which deplete irreversibly the defense mechanisms of cells and result in cell apoptosis [36]. The $\beta$-CS resin has a composition very similar to that of a commercial pulp protection material known as Theracal LC (containing 40-50 wt\% of Portland cement powder, $30-40$ wt\% of neutral or mildly acidic hydrophilic resin monomers, $5-10 \mathrm{wt} \%$ of a hydrophobic resin monomer (BisGMA) and $5-10 \mathrm{wt} \%$ of a hydrophilic filler). Indeed, the present results seem to be in accordance with those of Bortoluzzi et al. [33], who showed that Theracal LC caused a reduction in cell metabolism and protein expression when in contact with pulp cells. However, apart from $\beta$-CS resin, the drop in absorbance (MTT) was less than 50\% compared to the control cells groups, which may represent minor (reversible) cytotoxic effects [37].

Similar cell density and morphology were encountered for resin containing BAG (Fig. $2 \mathrm{C}$ ) and those containing the zincdoped polycarboxylate fillers (BAG-ZN and $\beta-C S-Z n)$ (Fig. 2D). These materials showed less cytotoxicity compared to the control RES and $\beta$-CS. Moreover, the resins BAG-Zn and $\beta$-CS-
Zn were able to induce an osteogenic effect with significant increase in expression of both markers (Runx-2 and ALP). Calcium deposits were observed using the alizarin staining technique in the BAG-Zn (Fig. 2E) and $\beta$-CS-Zn (Fig. 2F) resins.

In view of these results it is possible to confirm that the second null hypothesis, the addition of bioactive micro-fillers would cause increase in cytotoxicity and induce no differentiation in primary human mesenchymal stem cells (MSCs), should be partially rejected as these factors are associated with the chemical properties and composition of each single tested bioactive filler.

Recently, Ca-Si-based ceramics doped with specific therapeutic elements (Mg [38], $\mathrm{Zn} \mathrm{[39],} \mathrm{and} \mathrm{Sr} \mathrm{[40])} \mathrm{have} \mathrm{been}$ designed to improve their biological properties. In particular, $\mathrm{Zn}$ has been demonstrated to have a stimulatory effect on bone formation and an inhibitory effect on osteoclastic bone resorption [41]. Indeed, $\mathrm{Zn}$ ions appear to induce ALP activity, since ALP is a Zn-dependent enzyme [42]. Zinc deficiency induces arrest of bone growth, bone development, and jeopardizes the overall maintenance of bone health $[43,44]$. Yu et al. [45] showed that bioceramics doped with zinc (e.g. $\mathrm{Ca}_{2} \mathrm{ZnSi}_{2} \mathrm{O}_{7}$ ) enhances attachment, proliferation, differentiation and up-regulated bone marker gene expression of ALP and growth factor genes (e.g. IGF-I and TGF- $\beta 1$ ), compared to zinc-free silicates $\left(\mathrm{CaSiO}_{3}\right)$. Chesters [46] and Cousins [46] reported that zinc is a crucial trace element that induces several metabolic, cellular signaling pathways and gene expression for bone formation. Moreover, the incorporation of zinc into calcium phosphate cement significantly promotes pre-osteoblast proliferation and differentiation in vitro [47-50]. Furthermore, it was also suggested that zinc is involved in regulating the transcription of pre-osteoblast differentiation genes (e.g. Col-I, ALP and osteopontin) [51]. Hence, zinc is considered a promising agent for enhancing the boneforming ability of implant materials, which can be achieved by controlling the release of $\mathrm{Zn}$ ions.

\section{Conclusions}

The present study has demonstrated that the incorporation of the experimental fillers into resin-based materials makes them "bioactive" enough to induce apatite precipitation. However, only the resins containing the two zinc-doped bioactive fillers are able to maintain stable mechanical properties over time. In terms of biocompatibility and cells differentiation, the resins containing the zinc-doped fillers ( $\beta-C S-Z n$ and BAG-Zn) were the most promising as possible alternative pulp protection materials for use clinically.

\section{Acknowledgements}

This work was supported by the research grant INDI - "Programa de Consolidación de Indicadores: Fomento Plan Estatal CEU-UCH" 2014-2018 to Prof. Dr. Salvatore Sauro. This research was also in part supported by Project CNPq 407282/2013-0 (Bolsa PVE - Linha 2), UBC Start-UP funds to RMC. 


\section{R E F E R E N C E S}

[1] Innes NPT, Frencken JE, Bjorndal L, Buchalla W, Maltz M, Manton DJ, et al. Managing caries lesions: consensus recommendations on terminology. Adv Dent Res 2016;28:49-57.

[2] Sauro S, Osorio R, Watson TF, Toledano M. Influence of phosphoproteins' biomimetic analogs on remineralization of mineral-depleted resin-dentin interfaces created with ion-releasing resin-based systems. Dent Mater 2015;31:759-77.

[3] Abdullah D, Ford TR, Papaioannou S, Nicholson J, McDonald F. An evaluation of accelerated Portland cement as a restorative material. Biomaterials 2002;23:4001-10.

[4] Schwendicke F, Frencken JE, Bjorndal L, Buchalla W, Maltz M, Manton DJ, et al. Managing caries lesions: consensus recommendations on carious tissue removal. Adv Dent Res 2016;28:58-67.

[5] Banerjee A, Frencken JE, Schwendicke F, Innes NPT. Contemporary operative caries management: consensus recommendations on minimally invasive caries removal. $\mathrm{Br}$ Dent J 2017;223:215-22.

[6] Hashem D, Mannocci F, Patel S, Andiappan M, Brown JE, Watson TF, et al. Efficacy of calcium silicate indirect pulp capping; a randomized controlled clinical trial. J Dent Res 2015;94:562-8.

[7] Kim YK, Mai S, Mazzoni A, Liu Y, Tezvergil-Mutluay A, Takahashi $\mathrm{K}$, et al. Biomimetic remineralization as a progressive dehydration mechanism of collagen matrices-implications in the aging of resin-dentin bonds. Acta Biomater 2010;6:3729-39.

[8] Hench LL. Bioceramics and the origin of life. J Biomed Mater Res 1989;23:685-93.

[9] Kokubo T, Takadama H. How useful is SBF in predicting in vivo bone bioactivity. Biomaterials 2006;27:2907-15.

[10] Camilleri J, Montesin FE, Di Silvio L, Pitt Ford TR. The chemical constitution and biocompatibility of accelerated Portland cement for endodontic use. Int Endod J 2005;38:834-42

[11] Camilleri J. Investigation of biodentine as dentine replacement material. J Dent 2013;41:600-10.

[12] Bogen G, Kuttler S. Mineral trioxide aggregate obturation: a review and case series. J Endod 2009;35:777-90.

[13] Porter ML, Berto A, Primus CM, Watanabe I. Physical and chemical properties of new-generation endodontic materials. J Endod 2010;36:524-8.

[14] Nielsen MJ, Casey JA, VanderWeele RA, Vandewalle KS. Mechanical properties of new dental pulp-capping materials. Gen Dent 2016;64:44-8.

[15] Hebling J, Lessa FC, Nogueira I, Carvalho RM, Costa CA. Cytotoxicity of resin-based light-cured liners. Am J Dent 2009;22:137-42

[16] Hench LL. The story of bioglass. J Mater Sci Mater Med 2006;17:967-78.

[17] Sauro S, Thompson I, Watson TF. Effects of common dental materials used in preventive or operative dentistry on dentin permeability and remineralization. Oper Dent 2011;36:222-30

[18] Gendreau L, Barlow AP, Mason SC. Overview of the clinical evidence for use of NovaMin in providing relief from the pain of dentin hypersensitivity. J Clin Dent 2011;22:90-5.

[19] Milly H, Festy F, Andiappan M, Watson TF, Thompson I, Banerjee A. Surface pre-conditioning with bio-active glass air-abrasion can enhance enamel white spot lesion remineralisation. Dent Mater 2015;31:522-33.

[20] Sauro S, Osorio R, Watson TF, Toledano M. Therapeutic effects of novel resin bonding systems containing bioactive glasses on mineral-depleted areas within the bonded-dentine interface. J Mater Sci Mater Med 2012;23:1521-32.

[21] Sauro S, Osorio R, Fulgencio R, Watson TF, Cama G, Thompson I, et al. Remineralisation properties of innovative light-curable resin-based dental materials containing bioactive micro-fillers. J Mater Chem B 2013;1:2624-38.

[22] El-Askary FS, Botros SA, Abdelaziz Nassif MF, Özcan M. Flexural strength of nano-hybrid resin composite as a function of light attenuation distance and specimen dimension. J Adhes Sci Technol 2017;31:520-9.

[23] IIlie N, Hilton TJ, Heintze SD, Hickel R, Watts DC, Silikas N, et al. Academy of dental materials guidance-resin composites: part I-mechanical properties. Dent Mater 2017;33:880-94.

[24] Tsuda H, Arends J. Raman spectroscopy in dental research: a short review of recent studies. Adv Dent Res 1997;11:539-47.

[25] Blázquez-Prunera A, Díez JM, Gajardo R, Grancha S. Human mesenchymal stem cells maintain their phenotype, multipotentiality, and genetic stability when cultured using a defined xeno-free human plasma fraction. Stem Cell Res Ther 2017;8:103.

[26] Salgado VE, Cavalcante LM, Moraes RR, Davis HB, Ferracane JL, Schneider LF. Degradation of optical and surface properties of resin-based composites with distinct nanoparticle sizes but equivalent surface area. J Dent 2017;59:48-53.

[27] Ferracane JL. Hygroscopic and hydrolytic effects in dental polymer networks. Dent Mater 2006;22:211-22.

[28] Shahwan T, Zünbül B, Tunusoğlu O, Eroğlu AE. AAS, XRPD, SEM/EDS, and FTIR characterization of $\mathrm{Zn}^{2+}$ retention by calcite, calcite-kaolinite, and calcite-clinoptilolite minerals. J Colloid Interface Sci 2005;286:471-8.

[29] O’Donnell JNR, Schumacher GE, Antonucci JM, Skrtic D. Structure-composition-property relationships in polymeric amorphous calcium phosphate-based dental composites. Materials 2009;2:1929-54.

[30] Kamitakahara M, Kawashita M, Kokubo T, Nakamura T. Effect of polyacrylic acid on the apatite formation of a bioactive ceramic in a simulated body fluid: fundamental examination of the possibility of obtaining bioactive glass-ionomer cements for orthopaedic use. Biomaterials 2001;22:3191-6.

[31] Le HR, Chen KY, Wang CA. Effect of pH and temperature on the morphology and phases of co-precipitated hydroxyapatite. J Sol Gel Sci Technol 2012;61:592-9.

[32] Liu C, Huang Y, Shen W, Cui J. Kinetics of hydroxyapatite precipitation at pH 10-11. Biomaterials 2001;22:301-6.

[33] Bortoluzzi EA, Niu LN, Palani CD, El-Awady AR, Hammond BD, Pei DD, et al. Cytotoxicity and osteogenic potential of silicate calcium cements as potential protective materials for pulpal revascularization. Dent Mater 2015;31:1510-22.

[34] Van Landuyt KL, Krifka S, Hiller KA, Bolay C, Waha C, Van Meerbeek B, et al. Evaluation of cell responses toward adhesives with different photoinitiating systems. Dent Mater 2015;31:916-27.

[35] Sigusch BW, Pflaum T, Völpel A, Schinkel M, Jandt KD. The influence of various light curing units on the cytotoxicity of dental adhesives. Dent Mater 2009;25:1446-52.

[36] Engelmann J, Janke V, Volk J, Leuhausen G, Neuhoff NV, Schlegelberger B, et al. Effects of BisGMA on glutathione metabolism and apoptosis in human gingival fibroblasts in vitro. Biomaterials 2004;25:4573-80.

[37] Hebling J, Bianchi L, Basso FG, Scheffel DL, Soares DG, Carrilho MR, et al. Cytotoxicity of dimethyl sulfoxide (DMSO) in direct contact with odontoblast-like cells. Dent Mater 2015;31:399-405. 
[38] Wu CT, Chang JA, Wang JY, Ni SY, Zhai WY. Preparation and characteristics of a calcium magnesium silicate (bredigite) bioactive ceramic. Biomaterials 2005;26:2925-31.

[39] Ramaswamy Y, Wu CT, Zhou H, Zreiqat H. Biological response of human bone cells to zinc-modified Ca-Si-based ceramics. Acta Biomater 2008;4:1487-97.

[40] Wu CT, Ramaswamy Y, Kwik D, Zreiqat $\mathrm{H}$. The effect of strontium incorporation into $\mathrm{CaSiO}_{3}$ ceramics on their physical and biological properties. Biomaterials 2007;28:3171-81.

[41] Yamaguchi M, Oishi H, Suketa Y. Stimulatory effect of zinc on bone formation in tissue culture. Biochem Pharmacol 1987;36:4007-12.

[42] Habibovic P, Barralet JE. Bioinorganics and biomaterials. Bone repair. Acta Biomater 2011;7:3013-26.

[43] Hsieh HS, Navia JM. Zinc deficiency and bone formation in guinea pig alveolar implants. J Nutr 1980;110:1581-8.

[44] Oner G, Bhaumick B, Bala RM. Effect of zinc deficiency on serum somatomedin levels and skeletal growth in young rats. Endocrinology 1984;114:1860-3.

[45] Yu J, Li K, Zheng X, He D, Ye X, Wang M. In vitro and in vivo evaluation of zinc-modified Ca-Si-based ceramic coating for bone implants. PLoS One 2013;8:e57564.
[46] Chesters JK. Molecular biological approaches to nutrient-gene interactions. Proc Nutr Soc 1998;57:249-56.

[47] Cousins RJ. A role of zinc in the regulation of gene expression. Proc Nutr Soc 1998;57:307-11.

[48] Ito A, Kawamura H, Otsuka M, Ikeuchi M, Ohgushi H, Ishikawa $\mathrm{K}$, et al. Zinc-releasing calcium phosphate for stimulating bone formation. Mater Sci Eng C Biomim Supramol Syst 2002;22:21-5.

[49] Kawamura H, Ito A, Miyakawa S, Layrolle P, Ojima K, Ichinose $\mathrm{N}$, et al. Stimulatory effect of zinc-releasing calcium phosphate implant on bone formation in rabbit femora. J Biomed Mater Res 2000;50:184-90.

[50] Ito A, Otsuka M, Kawamura H, Ikeuchi M, Ohgushi H, Sogo Y, et al. Zinc-containing tricalcium phosphate and related materials for promoting bone formation. Curr Appl Phys 2005;5:402-6.

[51] Kwun IS, Cho YE, Lomeda RA, Shin HI, Choi JY, Kang YH, et al. Zinc deficiency suppresses matrix mineralization and retards osteogenesis transiently with catch-up possibly through Runx 2 modulation. Bone 2010;46:732-41. 